\title{
UTOPIA E MESSIANISMO NA LITERATURA HISPANO-AMERICANA COLONIAL
}

Rogério Mendes Coelho ${ }^{1}$

Resumo: 0 presente trabalho apresenta 0 estudo de uma das configurações discursivas mais emblemáticas que descreveram as realidades americanas durante o período colonial: os relatos de Cristobal Colón. 0 foco do presente artigo consiste na problematização dos escritos do navegador não apenas como discursos de fundação do espaço americano, onde perspectivas como história e ficção; imitação e desvio se confundem, estabelecendo as bases interpretativas das realidades americanas, mas, sobretudo, o desenvolvimento da imaginação como importante instrumento, tanto para fundamentar a base do pensamento político moderno quanto para fundamentar o processo de formação das sociedades americanas no século XVI.

Palavras-Chave: Relatos de Viagem; Imaginação; Século XVI.

Resúmen: El presente trabajo presenta el estudio de una de las configuraciones más emblemáticas que describieron las realidades americanas durante el periodo colonial: Los relatos de Cristóbal Colón. El enfoque del presente artículo consiste en la problematización de los escritos del navegador no sólo como discursos de fundación del espacio americano, donde perspectivas como la historia y ficción; imitación y desvío se confunden, estableciendo las bases interpretativas de las realidades americanas, pero, sobretodo, el desarrollo de la imaginación que fue importante tanto para fundamentar la base del pensamiento político moderno cuanto para fundamentar el proceso de formación de las sociedades americanas.

Palabras-Llave: Siglo XVI; Relatos de viaje; Utopía.

Um dos focos dos projetos expansionistas nos séculos XV e XVI consistiu na necessidade de difundir o cristianismo. Ou seja, além da expansão de fronteiras políticas e mercantis, homens como Colón lançaram-se em mares ignotos movidos por um ideal "epopéico" de propagação dos valores cristãos. Para muitos historiadores, em essência, uma iniciativa semelhante ao ímpeto das cruzadas medievais.

De fato, é possível observar, além dos distanciamentos, aproximações entre o espírito das cruzadas e alguma das incursões náuticas no século XVI. 0 que não surpreende, haja vista homens como o explorador Cristobal Colón possuírem ainda no século XVI valores medievais. Inclusive, é possível observar, por exemplo, aproximações entrenó espírito das cruzadas e as incursões náuticas do almirante Colón na ocasião em que acreditou, por meio do encon-

1 Professor de Literatura Hispano-Americana da Universidade Federal do Rio Grande do Norte (UFRN/CERES); doutorando em Teoria da Literatura pela Universidade Federal de Pernambuco (UFPE); endereço eletrônico: rogeriomendz@yahoo.com.br. 
tro com a América, ter encontrado o Éden e, com o feito, ambicionou estabelecer, em definitivo, a dimensão religiosa Una - Católica. 0 que não surpreenderia, pois, a orientação religiosa/imaginário do navegador italiano a serviço da Coroa Espanhola relacionava-se a uma perspectiva redentora e milenarista. Desse modo, propagar a fé e adquirir riquezas a partir do encontro e conquista de territórios pareceu conveniente e ideal para o arrojo e ousadia de homens como Colón, dispostos a conciliar interesses materiais, políticos e espirituais.

\begin{abstract}
[...] Vuestras Altezas, como católicos cristianos y Príncipes amadores de la santa fe cristiana y acrecentadores de ella y enemigos de la secta de Mahoma y de todas idolatrías y herejías, pensaron de enviarme a mí, Cristóbal Colón, a alas dichas partidas de India para ver los [...] pueblos y tierras y la disposición de ellas y de todo y la manera que se pudiera tener para la conversión de ellas a nuestra santa fe; y ordenaron que yo no fuese por tierra al Oriente, por donde se costumbra de andar, salvo por el camino de Occidente, por donde hasta hoy no sabemos por cierta fe que haya pasado nadie (COLÓN, 2003, p. 2).
\end{abstract}

Da Idade Média à época do encontro com a América, no século XVI, a Europa ainda situava deus no centro da razão dos homens que julgava conhecer a verdadeira "única" forma de religiosidade. Unilateralidade que colaborou para reiterar o imaginário cristão no continente americano como insígnia capaz de responsabilizar-se pela conduta e destino de homens a exemplo da mentalidade de navegadores e exploradores europeus, leais á Coroa e fiéis à Igreja. Relação que influenciou diretamente a visão de mundo de cada indivíduo e navegador na interpretação de cada experiência e descobertas, incluindo-se a América quando, na ocasião de seu encontro, tomou a forma do Éden, de acordo com as expectativas e imaginação de seus intérpretes. Por isso não surpreende que fosse comum e fizesse sentido existir e acreditar em profecias que se responsabilizariam pela melhor sorte da humanidade nem poderia surpreender Colón situar-se como profeta numa revelação que poderia suprimir grande parte dos males vividos pelo Velho Mundo. Foi imbuído nesse sentimento, misto de fé e esperança, que Colón investiu-se em mares ignotos no ímpeto de explorar espaços e levou adiante o "significado e a vontade" das palavras de Deus como homem de fé.

Para Janice Teodoro, em "América Barroca" (2004), o navegador, imerso no sentimento místico que orientava a época, sentiu-se, sob a égide do cristianismo, quando pensou ter localizado o "Paraíso Terrestre", responsável pela possibilidade de "redenção" do Ocidente. Mais que um casual encontro ${ }^{2}$ a América significou para Colón o cumprimento de uma profecia; obsessão que 0

2 Ver O'GORMAN, Edmundo. A invenção da América. Trad. Ana Maria Martinez Corrêa e Manoel Lelo Bellotto. São Paulo: UNESP, 1992. 
navegador acreditou ser porta-voz. Tanto que a impressão que se tem ao analisar os textos é que a imagem da Terra Santa suscitada pelo navegador atrelou-se, principalmente, ao interesse de um homem em imortalizar-se como 0 responsável por encontrar o "elo perdido" do Ocidente.

López (2006) acrescenta que o sentimento de Colón vinculava-se a uma anterioridade para muitos desconhecida ao recordar os estudos dos escritos bíblicos do navegador ao lado do padre Gaspar Gorricio quando buscava a confirmação do "significado" de suas viagens como "prenúncio" místico. "Confirmação" e "prenúncio", inclusive, que o navegador italiano procurou "fundamentar" no Libro de las Profecías ${ }^{3}$. Dessa maneira, Colón acreditou, ao explorar o continente americano, que cumpria o que estava escrito nas sagradas escrituras. Ou seja, acreditou ser o mensageiro de Deus ao pensar ter encontrado o Paraíso na América. Dessa maneira,

[...] a América mostrou ser um mundo novo no sentido de uma ampliação não previsível da velha casa ou, se se preferir, da inserção nela de uma parcela da realidade universal, considerada até então como de domínio exclusivo de Deus (O'GORM AN, 1992, p. 198).

A função do Libro de las Profecías além de promulgar a "revelação" de espaços sagrados e perdidos teve a intenção de homologá-los ao tentar persuadir os Reis Católicos de que o encontro com a América era, de fato, a confirmação de profecias. Tanto que Colón anexou o Libro de las Profecías a outros documentos compromissados com o testemunho da verdade entregues aos Reis após as expedições. Ao fazê-lo, o navegador buscou respaldo necessário para reconhecer a "revelação" e firmar-se responsável pela boa nova.

Apesar do esforço de Colón para reconhecer a existência do Paraíso Terrestre é possível que os Reis Católicos, representantes de Deus na terra, tenham rejeitado a idéia messiânica porque a "revelação" de Colón prejudicaria a estabilidade política e administrativa dos reinos. Ou seja, viabilizar o milagre da redenção significaria relegar a segundo plano a importância (do papel) dos Reis nas vidas dos homens.

De qualquer maneira, as afirmações de Colón a respeito do continente americano serviram para ampliar as possibilidades de entendimento das terras

3 Os estudos levados a cabo junto com o Padre Gorricio resultaram na escritura de um caderno de citações proféticas. 0 livro tentou fornecer, entre diversas referências - salmos, excertos dos Apóstolos, palavras de Santo Agostinho, Jeremias, Isaías, Gênese e Apocalipse -, sugestões e indicações sobre o devir e a salvação no plano terrestre. Salvação que acreditou Colón intermediar ao acreditar ter localizado ao visualizar semelhanças no Novo Mundo com os indícios a que se referiam às palavras dos profetas. 
descobertas. Pensar a respeito do que apresentou Colón fez com que muitos homens pensassem a respeito de sua condição e organização social. Basta observar que grande parte das Utopias escritas no século XVI tenha se referido muitas vezes ao encontro de Ollhas Perdidas e 0 relatos desses encontros. Muitos fizeram menções diretas sobre a América como é o caso de Thomas More - A Utopia - e Tommaso Campanella - "A Cidade do Sol". Porém, independente dos desdobramentos possíveis, o fato é que as subjetividades na interpretação de Colón não foram suficientes para empreender a idéia de salvação porque ficou evidente 0 fracasso da razão primeira do financiamento das expedições que se relacionavam a buscas materiais - nesse ponto muitos inferem que a idéia do Paraíso foi exposta por Colón no intuito de encobrir o fracasso das investidas. Nesse caso, é bom salientar que antes da fixação material por ouro que justificava a empreitada da exploração.

No es la población salvo allá más adentro, adonde dicen otros hombres que yo traigo que está el rey que trae mucho oro; y yo de mañana quiero ir tanto avante que halle la población y vea o haya lengua con este rey que, según éstos dan las señas, él señorea todas estas islas comarcanas y va vestido trae sobre sí mucho oro; aunque yo no doy mucha fe a sus decires, así por no los entender yo bien, como en cognoscer que ellos son tan pobres de oro que cualquiera poco que este rey traiga les parece a ellos mucho (COLÓN, 2003, p. 13).

Colón era um homem crente em busca de sua verdade e que acreditava estar apto para conhecê-la e difundi-la. Tanto que anexo aos diários de navegação estava o Libro de las Profecias entregue aos Reis Católicos. Colón, desse modo, autoproclamava-se como "[...] homem comum e iluminado que, com a ajuda de outros homens iluminados, tinha o dom de antever o amanhã ou a razão resplandecente que se serviria útil ao explicar o passado e dar um sentido final à história humana", como sugere Cordiviola (2005, p. 70). 0 que leva a crer que Colón, antes de estar a serviço dos Reis, estava a serviço dos desígnios de Deus, envolvido em outras descobertas ademais das imediatas e comuns.

Colón acreditava ser uma espécie de "escolhido" por Deus para revelar novos rumos para a Humanidade. 0 navegador genovês também acreditava que o fato de ser navegador o vocacionava a intermediar novas relações alémmar. Ao escrever o Libro de las Profecias, respaldado por afirmações de profetas justificou seu intento. Para o descobrir a América significou descobrir um plano de Deus, ao reafirmar as previsões de profetas como Isaías: "en efecto, las islas me aguardan y las naves del mar en primer lugar, para que conduzca a tus hijos desde los lejos" (COLÓN apud LÓPEZ, 2006, p. 51). Como acreditava ser o mediador dos mundos internalizou as palavras do profeta e acreditou ser digno da incumbência de conduzir "los hijos" às Ilhas, à América. Em Jeremias 
$31^{4}$, o genovês reafirmou a pertinência das profecias e o papel por ele assumido como "mediador" de uma nova Era. É possível que Colón, ao assumir o compromisso com os Reis de encontrar uma nova rota para as Índias na verdade estava imbuído em encontrar, sobretudo, as llhas anunciadas pelos profetas. Como navegador, conciliar convicções pessoais e missões sociais, talvez tenha sido, de fato, a confirmação necessária para respaldar seus interesses. Então, o que haveria de ilegítimo ou absurdo em suas palavras e interpretações?

A Bíblia preanuncia aquilo que o navegante encontrará no seu percurso, e a geografia de mil maneiras confirma o que fora previsto muito antes, e que, portanto, era indisputável, por obedecer desígnios divinos (CORDIVIOLA, 2005, p. 68).

Percebe-se, com isso, que Colón foi, sobretudo, fiel às suas crenças e responsabilidades e fez delas tentativa de conversão de um mundo. 0 que significaria a concretização do sonho de encontrar o Paraíso na terra. Dessa maneira, que ao projetar o Paraíso Terrestre na América Colón deixou inscrito em seus diários não o que ele viu no continente americano, mas o que gostaria de ver, de acordo com o repertório de pressentimentos, imaginações e desejos coletivos perpassados de gerações e gerações entre frustrações e ansiedades que se fizeram materializáveis em semelhanças até então não experenciadas. Desse modo, diante da urgência da revelação e condição em que se encontravam os homens medievais, do ponto de vista econômico e social, pouco importava saber se o navegador ao desembarcar em $1492 \mathrm{em}$ terras desconhecidas chegava a outro continente: prevaleceu a impressão de que se preferiu manter os sonhos de uma civilização.

O mito, a repetição da repetição, se inscreve como força antecipatória no fluxo
linear da história cristã; ensaia eternos retornos que desordenam e desviam os
sentidos do tempo, invoca estranhas continuidades que parecem se configurar
no além da história e da geografia. Cria uma outra esfera de interpretação, que,
apelando a tradição e ao divino, não apenas se contrapõe à banalidade do real,
mas também ajuda a redefinir essa mesma noção de real (CORDIVIOLA, 2005, p.
87).

0 que se destaca nas palavras do almirante genovês firma-se como oportunidade de reviver e conquistar "origens" e torná-las tão inquestionáveis quanto profícuas para o desenvolvimento da história do homem. Pois, os cristãos há muito buscavam o Paraíso quando ele não se mostrou ao alcance de olhos que pertenciam a corpos e espíritos que, indubitavelmente, se achavam

4 "Oid, gentes, la palabra del Señor en las islas que están lejos" (COLÓN apud LÓPEZ, 2006, p. 51). 
merecedores do consolo de angústias e necessidades, materiais e espirituais supridas.

El propio sentido de insatisfacción de la cristiandad del siglo XV halló su expresión en la ansia de volver a una situación más favorable. La vuelta debía ser al perdido paraíso cristiano, o a la Edad de Oro de los antepasados, 0 a alguna engañosa combinación de ambos (ELUOTT, 2000, p. 44).

Dessa maneira, a "descoberta" do navegador apresentou-se revolucionária e providente, pois, a imagem e a possibilidade de redenção habitava desde há muito a imaginação de cidadãos comuns, nobres, navegadores, exploradores e povoadores do Ocidente como obsessão. Obsessão por representar e indicar o recomeço que teria a função de livrar os homens dos "pecados" cometidos que obstaculizavam a realidade em curso.

Reviver esse tempo, reintegrá-lo o mais freqüente possível, assistir novamente ao espetáculo das obras divinas, reencontrar os Entes Sobrenaturais e reaprender sua lição criadora é o desejo que se pode ler como em filigrana em todas as reiterações rituais dos mitos. Em suma, os mitos revelam que o mundo, o homem e a vida têm uma origem e uma história sobrenaturais, e que essa história é significativa, preciosa e exemplar (ELIADE, 2004, p. 22).

No entanto, o que fez Cristóbal Colón acreditar que estava diante de Paraíso Terrestre? Ou, ao menos, quais os elementos além de sua convicção influenciaram e fizeram com que o espaço americano se tornasse algo próximo ou a sua própria materialização?

Ora, a idéia desse mundo resguardado de toda espécie de calamidade e padeci-
mentos físicos, tanto quanto a outra, que ela se enlaça estreitamente, da longe-
vidade extrema dos seus moradores, tende a entrosar-se, muitas vezes, na inspi-
ração dos velhos motivos edênicos, tais como aparecem principalmente na
literatura devota da Idade Média. A simples presença do desconhecido e do mis-
tério poderia, aliás, encaminhar sobre esse rumo as imaginações (HOLANDA,
1996, p. 283).

Desse modo, a imaginação deu sentido a América. Colón pensou encontrar o Paraíso com base em indícios literários pré-existentes e semelhanças testemunhadas com os olhos da fé. O que para a época foi "lícito", "legítimo" apesar das palavras de Colón terem sido meras especulações fundamentadas em convicções pessoais e analogias feitas pela ausência de recursos lingüísticos para explicar um universo distinto. Em verdade, a América foi uma realidade material que não havia sido experenciada - Literaturas - e que foi confundida com outra realidade - profecias -igualmente nunca vista e experenciada, 0 Paraíso, o que causou espanto e entusiasmo. Prevaleceu um Dever Ser ao invés de uma nova experiência com a realidade. 
Uma realidade que se fundamentava como imaginação em duas perspectivas distintas e convergentes: a herança de um imaginário anterior ao descobrimento e a necessidade de reatualizá-lo, o que se tornou possível a partir do "descobrimento". Colón viabilizou as duas perspectivas ao interpretar o espaço americano. Desse modo, mais do que representar a vontade de Deus é possível que ele tenha representado a infelicidade e a impaciência de homens com a realidade que o cercava quando pensou ter encontrado o "Paraíso".

0 resultado é que uns, meio desenganados, [...] movidos por uma desordenada impaciência, procuravam ou já cuidavam ter encontrado na vida presente o que os outros aguardavam na futura, de sorte que o mundo, para suas imaginações, se convertia num cenário prenhe de maravilhas (HOLANDA, 1996, p. 4).

Por isso, não seria exagero admitir que, caso a América não existisse àquelas alturas, seria necessário inventá-la.

La invención del otro como creación, alegoría, leyenda, fábula o simple mentira inscribe, poco a poco, el Nuevo Mundo en el ideal de un deber ser, mítico primero, utópico luego. Esta idealidad de contraponer al ser empírico que la invención americana va ratificando al mismo tiempo en el inventário de la nueva realidad abordada, vocación etnológica "avant la lettre" de cronistas y padres misioneros que integra y completa el soñar despierto de la utopía (AINSA, 1998, p. 34).

Uma via possível por meio do "milagre" da semelhança e que se responsabilizou por conciliar bases do pensamento lógico e mágico. A semelhança que, segundo Foucault (1987), desempenhou importante papel no século XVI por conduzir a exegese e a interpretação dos homens ao "organizar" o jogo simbólico das formas. 0 que faz sentido ao perceber os esforços dos navegadores ao tentar descrever os novos mundos. Novos mundos que reavivaram, por meio da linguagem, o que dificilmente poderia conceber-se: o Paraíso Terrestre ou a sua possibilidade. Universo que se assemelhou ao que de mais maravilhoso poderia existir para um homem que acreditava no além.

O mundo enrolava-se sobre si mesmo: a terra repetindo o céu, os rostos miran-
do-se nas estrelas e a erva envolvendo suas hastes os segredos que serviam ao
homem. A pintura imitava o espaço. E a representação - fosse ela festa ou saber
- se dava como repetição: teatro da vida ou espelho do mundo, tal era o título
de toda linguagem, sua maneira de anunciar-se e de formular seu direito de falar
(FOUCAULT, 1987, p. 33).

Mais que uma revelação, os escritos de Colón desvelaram-se na tentativa de reavivar o desejo de saldar uma antiga dívida do homem para consigo mesmo após séculos de infelicidades, buscas e insuficiências. A importância da projeção de Colón consistiu em proporcionar, mesmo que por alguns instantes, a oportunidade de os homens redimirem-se perante Deus dos maus procedi- 
mentos e os mal-estares causados por eles próprios a si mesmos. 0 encontro com a América, pelas "semelhanças" com o Paraíso perdido, poderia significar um sinal divino de consentimento para recomeçar uma nova fase. Por isso, não seriam absurdas as relações que fez Colón, mesmo ele representando anseios de poder e riqueza. De qualquer forma, é nesta aparente combinação entre 0 divino e o terreal, entre o espiritual e o material, que o sonho tentou acomodar-se no continente recém-descoberto: a oportunidade propícia para a sua materialização.

Independente das intenções e percursos, parece que o encontro de Colón com o "Paraíso" esteve mais relacionado à certeza de suas convicções do que a preocupação de seguir a lógica das coordenadas marítimas que o levariam ao Éden. Talvez, o fato de existirem indícios sobre a localização do Paraíso ao Oriente não fossem suficientes para desvirtuar outras possibilidades. Mesmo porque, por meio da ciência de que o mundo era esférico, a idéia sobre 0 Oriente poderia relativizar-se de acordo com referências de origem e caminho. Mais relevante foi chegar e desembarcar em um destino e perceber sugestões semelhantes a de suas convicções e tentar conciliá-las com o compromisso institucional. Convicções, inclusive, compatíveis e associáveis a palavras proféticas que norteavam a razão da época. Convicções, no entanto, que apesar de plausíveis e justificáveis, poderiam limitar-se a devaneios, frutos de uma imaginação que gerou obsessão.

O Senhor, teu Deus, te fez entrar numa terra boa, terra de torrentes, de fontes, de águas subterrâneas, jorrando na planície e na montanha, terra de trigo e de cevada, de vinhas, figueiras e romãzeiras, terra de óleo de oliva e de mel (DEUTERONÔMIO, 8, 7).

[...] porque es cierto que la hermosura de la tierra de estas islas, así de montes e sierras y aguas, como de vegas donde hay ríos cabdales, es tal la vista que ninguna otra tierra que sol escaliente puede ser mejor al parecer ni tan fermosa [...] (COLÓN, 2003, p. 73).

A impressão que se tem ao examinar os indícios que levaram o genovês ao escrever como escreveu ao interpretar a América marca "[...] a imaginação como ferramenta útil para dar explicação não somente ao desconhecido, mas também para tentar justificar o que não se queria admitir como evidente" (LÓPEZ, 2006, p. 48): o Novo Mundo como espaço distinto e inimaginável e descrição do espaço realizada pelo navegador fosse tão-somente a descrição de outra realidade; uma realidade que ele gostaria de testemunhar, que poderia ou não ser divina, a depender de quem e por quais razões poderia interpretá-las dessa maneira. 0 que leva a crer que as realidades podem tornar-se divinas quando se acredita que elas são semelhantes ao que desejamos e acreditamos como tal. 
É possível que a idéia do Paraíso, de fato, tenha sido uma espécie de representação, semiologia capaz de tornar legível e legítimo espaço até então inconcebível, porém, conveniente e reconhecível como conviç̧ão, esperança e realidade se demonstrado e comprovado. Uma necessidade, uma perspectiva que agradaria tanto os leitores quanto o escritor. Desse modo, a expectativa de muitos leitores somada à convicção do hermeneuta italiano fundiu-se em uma estratégia retórica que articulou idéias preestabelecidas pelo imaginário do Ocidente. Assim, não seria exagero considerar que encontrar o continente americano foi uma oportunidade que materializou o mito, de acordo com devaneios e necessidades, por meio de uma linguagem fundamentada na busca por felicidade e redenção. Sonho que se queria possível enquanto vida os homens tivessem.

A religiosidade dessa experiência deve-se ao fato de que, ao re-atualizar os eventos fabulosos, exaltantes, significativos, assiste-se novamente às obras criadoras dos Entes Sobrenaturais; deixa-se de existir no mundo de todos os dias e penetra-se num mundo transfigurado, auroral, impregnado da presença dos Entes Sobrenaturais. Não se trata de uma comemoração dos eventos míticos mas de sua reiteração. 0 indivíduo evoca a presença dos personagens dos mitos e tornase contemporâneos deles. Isso implica igualmente que ele deixa de viver no tempo cronológico, passando a viver no Tempo primordial, no Tempo em que 0 evento teve lugar pela primeira vez (ELIADE, 2004, p. 22).

0 que poderia ser oportuno. A fórmula era simples: considerar a América como possibilidade de felicidade e redenção a partir do resgate de idéias edênicas. 0 mito da terra incógnita decorrente da sensação de viver em um universo incompleto, de acordo com as promessas de imaginários, sonhos de homens que produziram Literatura. Seria a imaginação um transtorno necessário? Não importa. Seja qual for a resposta estará, assim como esteve até aqui, ao se tratar de futuro, o desejo por um lugar seguro e maravilhoso não foi nem será descabido. Um futuro que pretensa e curiosamente foi delineado pelos antigos.

Pelos sonhos, as diversas moradas de nossa vida se interpenetram e guardam os tesouros dos dias antigos. Quando, na nova casa, retornam as lembranças das antigas moradas, transportamo-nos ao país da Infância Imóvel, imóvel como 0 Imemorial. Vivemos fixações, fixações de felicidade. Reconfortamo-nos ao reviver lembranças de proteção (BACHELARD, 1993, p. 25).

Seja como for, não deve ter sido simples para o navegador italiano lidar com outra natureza. Pois, a imagem do Paraíso (re)suscitada por Colón relacionou-se à dificuldade de identificar e reconhecer uma realidade distinta. Pois, até então, os europeus bastavam-se. Não esperavam eles conscientizarem-se de que não estavam sós e que não passaram de meros componentes integran- 
do um sistema maior de convivência e realidade. É possível que inserir a América no patrimônio do imaginário do Ocidente tenha sido uma reação oportuna na tentativa de manter o mundo uno e sob controle. De toda forma, mais um transtorno firmado pela imaginação.

\section{REFERÊNCIAS}

AINSA, Fernando. De la Edad de Oro al El Dorado. Génesis del Discurso Utópico Americano. MéxiCO: FCE, 1992.

BACHELARD, Gaston. A poética do espaço. Trad. Antonio da Costa Leal; Lídia do Valle Santos Leal. São Paulo: Martins Fontes, 1993.

COLÓN, Cristobal. Los Cuatro Viajes del Almirante y su Testamento. Disponível em: http:// www.cervantesvirtual.com/servelet/sirveobras/50362733173581464260046/index.htm_. Acesso em: 10 jun. 2003.

COLÓN, Cristobal. Libro de las Profecías. Juan Fernández Valverde (Org.). Madrid: Alianza Editorial; Sevilla: Universidad de Sevilla, 1992.

CORDIVIOLA, Alfredo. Um mundo singular. Imaginação, memória e conflito na literatura hispano-americana do século XVI. Recife: PPGL/UFPE, 2005.

ELIADE, M ircea. Mito e realidade. Trad. Póla Civelli. São Paulo: Perspectiva, 2004.

ELUOTT, Jonh H. El Viejo M undo y el Nuevo (1492-1650). Madrid: Alianza Editorial, 2000.

FOUCAULT, M ichel. As palavras e as coisas. Uma arqueologia das ciências humanas. Trad. Salma Tannus M uchail. São Paulo: Martins Fontes, 1987.

HOLANDA, Sérgio Buarque de. Raízes do Brasil. In: SANTIAGO, Silviano. (Org.). Intérpretes do Brasil, t. 2. Rio de Janeiro: Nova Aguilar, 2002.

HOLANDA, Sérgio Buarque de. Visão do paraíso: os motivos edênicos no descobrimento e colonização do Brasil. São Paulo: Brasiliense, 1996.

LÓPEZ, Juan Ignácio Jurado-Centurión. A forja da identidade através da literatura colonial dos séculos xvi e xvi: navegantes, cronistas e religiosos no Novo Mundo. Dissertação de Mestrado orientada pelo Professor Dr. Alfredo Cordiviola (UFPE) e apresentada ao Departamento de PósGraduação em Letras da Universidade Federal de Pernambuco. Recife. 2006.

O'GORM AN, Edmundo. Invenção da América. Trad. Ana Maria Martinez; Manoel Lelo Bellotto. São Paulo: UNESP, 1992.

THEODORE, Janice. América barroca. São Paulo: Nova Fronteira/EdUSP, 1992. 